\title{
Pemetaan Profil Mahasiswa Untuk Peningkatan Strategi Promosi Perguruan Tinggi Menggunakan Predictive Apriori
}

\author{
Irfan Pratama1, Putri Taqwa Prasetyaningrum² \\ Program Studi Sistem Informasi \\ Universitas Mercu Buana Yogyakarta \\ Yogyakarta, Indonesia

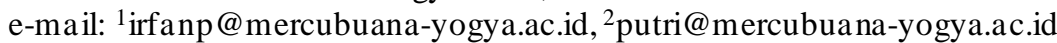 \\ Diajukan: 8 Februari 2021; Direvisi: 28 Maret 2021; Diterima: 31 Maret 2021
}

\begin{abstract}
Abstrak
Program promosi melalui berbagai media untuk meningkatkan dan menguatkan rekrutmen mahasiswa yang terdistribusi pada setiap program studi secara ideal dan setara diperlukan untuk membuat perguruan tinggi selalu bertumbuh. Demografis mahasiswa dapat menjadi karakteristik khusus dalam memilih program studi. Begitu pun lata belakang pendidikan mahasiswa dan keluarga. Berdasarkan masalah yang telah dikemukakan sebelumnya, maka peneliti tertarik untuk melakukan penelitian terkait data pendaftaran mahasiswa. Secara spesifik pengolahan terhadap data secara konseptual dapat dilakukan menggunakan proses Data Mining. Salah satu proses dari Data Mining yang dapat memberikan pengetahuan tentang keterkaitan antar variabel data adalah Association-Rule Mining. Metode yang digunakan yaitu Predictive Apriori sebagai metode asosiasi untuk mengekstrak profil mahasiswa dari universitas untuk mendapatkan wawasan yang lebihbaik tentang apa yang harus dilakukan timpemasaran untuk memperkuat kampanye pemasaran. Data tersebut akan diolah sehing ga dapat dikenali karakteristik atau pola dari data-data yang ada dengan harapan dapat memberikan pengetahuan untuk dapat meningkatkan efektivitas promosi dan rekrutmen mahasiswa. Metode tersebut menghasilkan total 44456 rules, yang selanjutnya dilakukan filter berdasarkan rules yang mengandung atribut Prodi dan ni lai akurasi minimum 90\% (0.9). Rules yang dihasilkan akan dijadikan saran ajuan terhadap bagian pemasaran untuk melakukan pola roadshow atau promosi sesuai pola yang telah terbentuk.
\end{abstract}

Kata kunci: Association rule, Data mining, Pembelajaran mesin, Predictive Apriori.

\begin{abstract}
As a growing University, there is definitely a need for promotional programs through various media to increase and strengthen the recruitment of students who are distributed in each course of study ideally and equally. The demographic aspects of the studen ts may be a special characteristic in choosing a course of study. Based on the problems that have been raised before, the researchers are interested in conducting research related to student registration data. Specifically, the processing of data conceptually can be done using the Data Mining process. One of the processes of Data Mining that can provide knowledge about the interrelationship between data variables is Association-Rule Mining. Predictive Apriori used as an association method to extract student profiles from universities to gain better insight into what marketing teams should do to strengthen marketing campaigns. The results of this study are 44456 number of rules produced by the method, and then filtered by the containment of Prodi attribute and the minimum accuracy score of $90 \%$ (0.9). The rules that found and filtered then proposed to the marketing department to follow as the promotion pattern on their roadshow schedule.
\end{abstract}

Keywords: Association rule, Data mining, machine learning, Predictive Apriori.

\section{Pendahuluan}

Menurut data yang dikeluarkan FORLAP RISTEKDIKI, Indonesia memiliki lebih dari 3000 perguruan tinggi dan 585 di antaranya merupakan perguruan tinggi swasta dan masih banyak lagi jenis perguruan tinggi swasta lainnya seperti institut, akademi, dan politeknik. 127 di antaranya berada di D.I. Yogyakarta, tentunya lebih dari itu jika memasukkan PTN ke dalam perhitungan [1]. Dengan banyaknya institusi tersebut maka persaingan di antara mereka tentunya cukup tinggi. Artinya kerja tim marketing khususnya untuk PTS harus lebih keras agar bisa menarik dan membujuk calon mahasiswa untuk 
bergabung. Selain dari akreditasi lembaga, efektivitas dan efisiensi tim pemasaran dapat memberikan pengaruh yang sangat besar terhadap penerima an calon mahasiswa. Jadi, mereka butuh semacam strategi agar bisa unggul dari kompetitor lain dalam hal promosi atau kampanye pemasaran. Promosi atau kampanye pemasaran merupakan salah satu hal yang harus dilakukan untuk membawa kesuksesan bagi perusaha an atau institusi. Menurut Kotler dan Keller, Konsep pemasaran menekankan bahwa kunciuntuk menca paitujuan orga nisasi yang dinyatakan a dalah bahwa perusahaan harus lebih efektif daripada pesaing dalam menciptakan, menyampaikan, dan mengkomunika sikan nilai pelanggan ke pa sar sa saran yang dipilih [2]. Dengan penggunaan informasi yang tepat, cara promosi yang efektif atau ke mana tujuan kampanye pemasaran dapat ditentukan untuk mendapatkan hasil yang lebih baik.

Beberapa tahun belakangan terdapat suatu bidang ilmu yang sangat tren di dunia teknologi informasi yang terkait dengan bidang-bidang lain termasuk bisnis yaitu Data Science.Data Science adalah sebuah bidang ilmu yang secara khusus mempelajari data, khususnya data yang bersifat kuantitatif atau numerik baik yang terstruktur maupun tak terstruktur sehingga da ta -data tersebut dapat memberikan suatu pemahaman terkait masalah atau fakta yang ada [3][4]. Secara spesifik pengolahan terhadap data secara konseptual dapat dilakukan menggunakan proses Data Mining. Salah satu proses dari Data Mining yang dapat memberikan pengetahuan tentang keterkaitan antar variabel data adalah Association-Rule Mining. Association-Rule adalah sebuah pembelajaran mesin berbasis aturan untuk menemukan keterkaitan antar variabel data pada sebuah basis data atau kumpulan data. Pengetahuan yang dihasilkan dari proses ini a da lah kumpulan-kumpulan a turan yang menyatakan hubungan sebab akibat antar variabel data [5][6].

Ada beberapa metode yang digunakan untuk penambangan aturan asosiasi yaitu Apriori, FPGrowth, dan Predictive Apriori. Apriori akan baik digunakan jika ada hubungan antara atribut yang dianalisis. Dan salah satu penggunaan aturan asosiasi adalah untuk menganalisis perilaku pelanggan dan strategi promosi dan pemasaran produk menggunakan metode apriori[7][8][9][10]. Bentuk implementasi lain dari aturan a sosia si a dalah untuk mendukung strategi promosi perguruan tinggi menggunakan metode Apriori[11]. Penelitian tentang analisis pola penjualan produk juga menggunakan apriori sebagai metode dan menghasilkan 6 aturan terbaik dengan menggunakan dukungan minimum $40 \%$ dan kepercayaan minimum 60\%[10]. Penelitian[12] dilakukan dengan membandingkan waktu evaluasi antara metode a priori dan FP-growth terhadap penjualan paket sembako. Hasil penelitian menyatakan bahwa dengan metode a priori, a priori menghasilkan 8 aturan terbaik dengan dukungan minimum 0,06 dan kepercayaan minimum 0,01 dengan tingkat akurasi 35\%. Sedangkan metode FP-Growth menghasilkan 14 aturan terbaik dengan menggunakan minimal support 0,06 dengan tingkat akura si $84 \%$.

Universitas Mercu Buana Yogyakarta memiliki 13 program studipada jenjang sarjana (S1) dengan bidang keilmuannya masing-masing. Sebagai Universitas yang berkembang, pasti perlu adanya program promosi melalui berbagai media untuk meningkatkan dan menguatkan rekrutmen mahasiswa yang terdistribusi pada setiap program studi secara ideal dan setara. Daerah asal mahasiswa pelamar dimungkinkan dapat menjadi karakteristik khusus dalam memilih program studi. Begitu pun profil dari mahasiswa itu sendiri seperti a saljurusan, a sal sekolah dan lain-lain. Sehubungan dengan hal tersebut, maka untuk melakukan penguatan rekrutmen mahasiswa pada program studi tertentu dapat dilakukan dengan mengetahui karakteristik spesifik dari data mahasiswa sehingga dapat diharapkan hasil promosi yang tepat sasaran. Di mana pada sebelumnya kecenderungan promosi yang dilakukan masih seba tas mendatangikota - kota dengan frekuensi jumlah mahasiswa yang besar tanpa spesifik melihat keterkaitan antara minat calon mahasiswa terhadap Prodi, sehingga proses promosinya masih umum.

Oleh karena itu, penelitian ini akan dilakukan dengan memanfaatkan metode asosiasi untuk mengekstrak pola dari profil mahasiswa untuk mendapatkan wawasan yang lebih baik tentang apa yang harus dilakukan tim pemasaran untuk memperkuat kampanye pemasaran berikutnya. Data tersebut akan diolah sedemikian rupa sehingga dapat dikenali karakteristik atau pola dari data -data yang ada dengan harapan dapat memberikan pengetahuan untuk dapat meningkatkan efektivitas promosi dan rekrutmen mahasiswa. Metode Predictive Apriori dipilih karena metode tersebut merupakan bentuk yang lebih mutakhir dari metode Apriori. Diharapkan dengan mengimplementasikan metode yang lebih mutakhir maka hasil dari metode tersebut akan lebih baik.

\section{Metode Penelitian}

Pada tahap iniakan dijelaskan a lur darija lannya penelitian ini. Dimulai dengan pengambilan data atau Data Aqcuisition, kemudian tahap Pre-Processing untuk memastikan data siap digunakan, kemudian data yang telah bersih dan siap digunakan akan di ana lisis menggunakan metode Predictive Apriori untuk menda patkan aturan a sosia si berda sarkan dari da ta yang dimiliki, dan yang terakhir adalah interpretasi dari hasil analisis sesuai kebutuhan. Dia gram a lir dari jalannya penelitian ini dapat dilih at pada Gambar 1. 


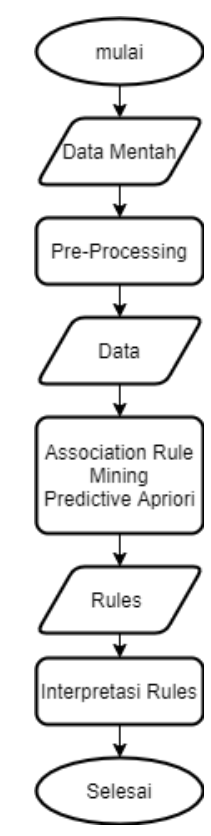

Gambar 1. Flowchart penelitian.

\subsection{Data}

Data yang digunakan pada penelitian ini a da lah data mahasiswa dari seluruh program studi sarjana (S1) yang ada di Universitas Mercu Buana Yogyakarta dari rentang tahun 2016 - 2020 dengan total data berjumlah 10.146 baris data. Tabel 1 berikut a da lah ga mbara numum daribentuk data yang digunakan pada penelitian ini.

Tabel 1. Sampeldata.

\begin{tabular}{cccccc}
\hline No & Prodi & Provinsi & Pendapatan orang Tua & Pekerjaan Orang Tua & Asal Sekolah \\
\hline 1 & Ilmu Komunikasi & JAMBI & $<1000000$ & Buruh & SMA Payakumbuh \\
\hline 2 & Informatika & JAMBI & $2000000-2500000$ & Lainnya & MA Nurul Hidayah \\
\hline 3 & Ilmu Komunikasi & JAMBI & $>3000000$ & Swasta & SMA N 2 Tanjung Jabung \\
\hline 4 & Psikologi & GORONTALO & $>3000000$ & PNS & MA Mubarok \\
\hline 5 & Psikologi & JAMBI & $1000000-2000000$ & PNS & SMA N 1 Tanjung jabung \\
\hline
\end{tabular}

\subsection{Pre-Processing}

Pada tahap Pre-Processing ini terdapat beberapa langkah yang dilakukan untuk mempersiapkan data mentah menjadi data yang siap digunakan untuk proses data mining selanjutnya. Langkah-langkah tersebut meliputi: pengisian missing values, dan transformasi data.

\subsubsection{Transformasi Data}

Pada tahap transformasi data ini, beberapa kolom data (atribut) akan ditransformasikan menjadi bentuk yang lebih general dan mudah untuk diproses. Bentuk transformasi yang akan dilakukan terhadap data mentah yang dimiliki adalah pada kolom Pendapatan Orang Tua dan Asal Sekolah. Seperti yang terlihat pada Tabel 1, data Asal sekolah masih berupa rincian a sal sekolah dari masing-masing maha siswa. Sehingga akan dikelompokkan menjadi 3 jenis sekolah yaitu SMA, SMK, dan MA. Begitu juga dengan kolom Pendapatan Orang Tua yang akan di transformasikan menjadi kode seperti $<1000000=\mathrm{A}, 100000$ $-2000000=\mathrm{B}, 2000000-2500000=\mathrm{C}, 2500000-3000000=\mathrm{D},>3000000=\mathrm{E}$. Tabel 2 berikut ini adalah contoh dari hasil transformasidataset.

Tabel 2. Hasil transformasidata.

\begin{tabular}{cccccc}
\hline No & Prodi & Provinsi & Pendapatan orang Tua & Pekerjaan Orang Tua & Asal Sekolah \\
\hline 1 & Ilmu Komunikasi & JAMBI & A & Buruh & LMA \\
\hline 2 & Informatika & JAMBI & C & Swasta & MA \\
\hline 3 & Ilmu Komunikasi & JAMBI & E & PNS & SMA \\
\hline 4 & Psikologi & GORONTALO & E & PNS & SMA \\
\hline 5 & Psikologi & JAMBI & B & &
\end{tabular}

Pemetaan Profil Mahasiswa Untuk Peningkatan Strategi Promosi Perguruan Tinggi Menggunakan Predictive Apriori (Irfan Pratama) 


\subsubsection{Pengisian Missing Values}

Dataset yang digunakan memiliki missing values pada bagian a sal sekolah, pendapatan orang tua dan pekerjaan orang tua, karena sifat form pada a sal sekolah saat pengisian data adalah text box. Sehingga dimungkinkan adanya ketidaklengkapan data yang diberikan. Sedangkan pada data pendapatan orang tua dan pekerjaan orang tua tidak di set sebagai required field sehingga juga diperbolehkan kosong. Agar data dapat digunakan dengan utuh tanpa ada yang dihapus karena mengandung missing values, dibutuhkan mekanisme untuk memperkirakan nilai untuk menggantikan missing values yang ada pada data tersebut. Terdapat berbagai mekanisme yang dapat dilakukan untuk menangani missing values yang terjadi pada sebuah dataset. Dari mekanisme yang sangat sederhana seperti menghapus baris data yang mengandung missing values yang akan mengakibatkan da ta berkurang sehingga informasi-informasi nya yang dapat di akuisisi juga berkurang. Terdapat juga sebuah mekanisme pengisian missing values menggunakan mean (untuk data numerik) a tau mode (untuk data nominal) yang tidak efektif untuk jumlah missing values yang banyak karena a kan menimbulkan bias. Hingga mekanisme mutakhir yang menggunakan machine learning [13]. Meka nisme pengisian missing values yang digunakan pada penelitian ini a da lah menggunakan metode K-NN [14][15]. Menggunakan tools RapidMiner dalam pengisian missing values, skema penanganan missing values menggunakan metode K-NN dapat dilihat pada Gambar 2 dan Ga mbar 3 berikut.

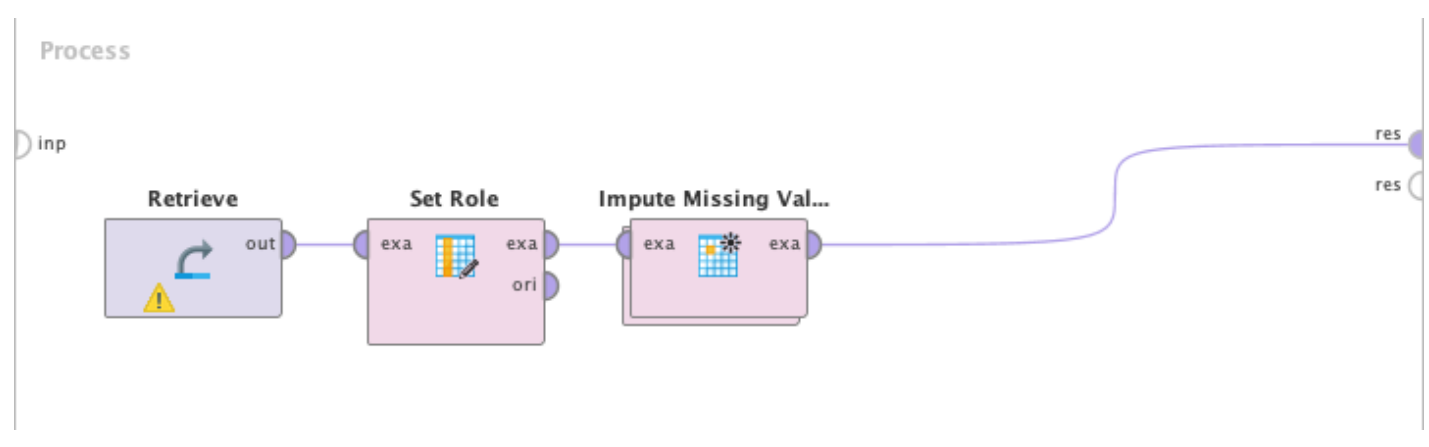

Gambar 2. Skema missing values imputation.

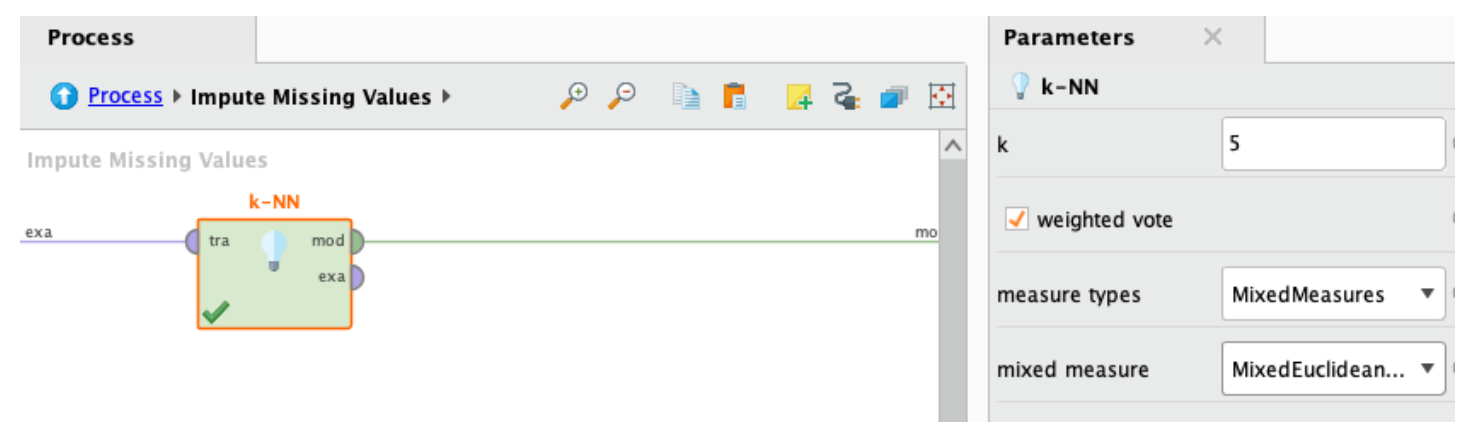

Gambar 3. Metode K-NN.

Pada Gambar 2 dapat dilihat skema pengisian missing values yang mengharuskan dataset yang akan diisi missing values-nya menggunakan metode K-NN untuk di set labelnya terlebih dahulu, karena penelitian ini ingin menonjolkan profiling mahasiswa untuk setiap Prodinya, sehingga label dari datanya akan ditujukan kepada da ta Prodi. Pada Gambar 3 dapat dilihat pengaturan paramet er untuk metode K-NN menggunakan $k=5$ dengan parameter lainnya bersifat default. Hasil perubahan dari pengisian missing values-nya dapat dilihat pada Gambar 4 dan Gambar 5 yang menunjukkan data sebelum dan pengisian missing values. 


\begin{tabular}{|l|l|l|l|l|l|}
\hline Row No. $\downarrow$ & PROV & PEKERJAAN & PENDAPAT... & ASAL SEKO... & PRODI \\
\hline 8461 & JAWA TENGAH & Lainnya & 1 & SMA & Psikologi \\
\hline 8460 & PAPUA BARAT & $?$ & 1 & SMA & Psikologi \\
\hline 8459 & JAWA TIMUR & Swasta & 1 & SMA & Akuntansi \\
\hline 8458 & PAPUA & Swasta & 3 & SMK & Manajemen \\
\hline 8457 & SUMATERA ... & PNS & 4 & SMA & Manajemen \\
\hline 8456 & DI YOGYAKA ... & PNS & 3 & SMK & Psikologi \\
\hline 8455 & PAPUA BARAT & PNS & 2 & SMK & Informatika \\
\hline 8454 & PAPUA BARAT & PNS & 4 & SMK & Ilmu Komuni... \\
\hline 8453 & SUMATERA ... & Lainnya & 1 & SMA & Psikologi \\
\hline 8452 & LAMPUNG & Swasta & 1 & MA & Psikologi \\
\hline 8451 & JAWA TENGAH & $?$ & 1 & SMA & Psikologi \\
\hline 8450 & DI YOGYAKA ... & Buruh & 0 & SMK & Ilmu Komuni... \\
\hline
\end{tabular}

Gambar 4. sebelum penanganan missing values

\begin{tabular}{|l|l|l|l|l|l|}
\hline Row No. $\downarrow$ & PROV & PEKERJAAN & PENDAPAT... & ASAL SEKO... & PRODI \\
\hline 8461 & JAWA TENGAH & Lainnya & 1 & SMA & Psikologi \\
\hline 8460 & PAPUA BARAT & Swasta & 1 & SMA & Psikologi \\
\hline 8459 & JAWA TIMUR & Swasta & 1 & SMA & Akuntansi \\
\hline 8458 & PAPUA & Swasta & 3 & SMK & Manajemen \\
\hline 8457 & SUMATERA ... & PNS & 4 & SMA & Manajemen \\
\hline 8456 & DI YOGYAKA... & PNS & 3 & SMK & Psikologi \\
\hline 8455 & PAPUA BARAT & PNS & 2 & SMK & Informatika \\
\hline 8454 & PAPUA BARAT & PNS & 4 & SMK & IImu Komuni... \\
\hline 8453 & SUMATERA ... & Lainnya & 1 & SMA & Psikologi \\
\hline 8452 & LAMPUNG & Swasta & 1 & MA & Psikologi \\
\hline 8451 & JAWA TENGAH & Lainnya & 1 & SMA & Psikologi \\
\hline 8450 & DI YOGYAKA... & Buruh & 0 & SMK & IImu Komuni... \\
\hline 8449 & SUMATERA ... & Lainnya & 3 & SMA & IImu Komuni... \\
\hline 8448 & JAWA TENGAH & Swasta & 1 & SMK & Peternakan \\
\hline
\end{tabular}

Gambar 5. Setelah Penanganan missing values menggunakan K-NN imputation.

\subsection{Predictive Apriori}

Predictive Apriori di kembangkan oleh Scheffer [16]. Metode ini menggunakan nilai support yang lebih besardan ditukar dengan nilai confidence yang lebih tinggi pula dan akurasidihitung dalam Bayesian Network. Hasil dari algoritma ini memaksimalkan nilai akurasi untuk data-data yang akan datang. Algoritma ini menghasilkan jumlah rules sesuai dengan yang di spesifika sikan oleh pengguna. Algoritma ini didefinisikan sebagai berikut:

Misalkan $D$ adalah database dimana $r$ adalah record individualyang diha silkan oleh proses statis $P$, misalkan $X \rightarrow Y$ menjadiaturan asosiasi. Akurasi prediktif $c(X \rightarrow Y)=\operatorname{Pr}(r$ memenuhi $Y \mid r$ memenuhi $X$ ) adalah probabilita s bersyarat dari $Y \subseteq r$ mengingat bahwa $X \subseteq r$ ketika distribusi $r$ diaturoleh $P$ [16].

Fungsi perhitungan akura si prediktif a dalah sebagaiberikut:

$$
E(c(r) \mid \hat{c}(r), s(X))=\frac{\int c B[c, s(X)](\hat{c}(r)) P(c) d c}{\int_{B}[c, S(X)](\hat{c}(r)) P(c) d c}
$$

Di mana $E(c(r) \mid \hat{c}(r), s(X))$ adalah akurasi prediktif yang diharapkan dari rule $r X \rightarrow Y$. nilai confidence dinotasikan sebagai $\hat{c}$ dan nilai support dari rule nya di notasikan sebagai $s(X)$.

Pada penelitian ini jumlah rules yang dinginkan adalah pada nilai maksimal dari yang bisa dihasilkan oleh data. Dengan menggunakan RapidMiner, skema Predictive Apriori dapat dilihat pada Gambar 5 . 


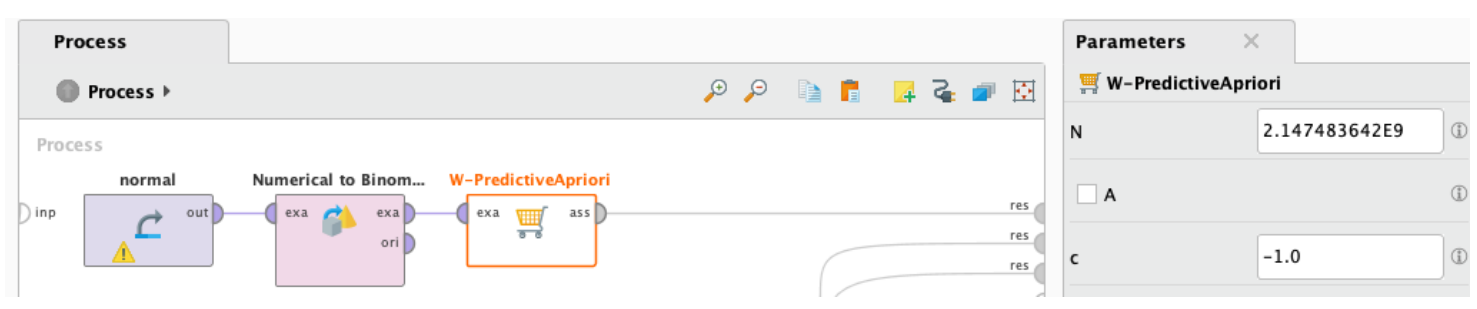

Gambar 6. Predictive Apriori.

Pada Gambar 5 dapat dilihat parameter Predictive Apriori pada jumlah rules diset pada nilai default dari yang diberikan oleh RapidMiner yaitu 2.147.483.642, meskipun jumlah rules yang dihasilkan mungkin saja tidak akan sebanyak itu karena tergantung dari yang ditemukan berdasarkan data yang dimiliki.

\subsection{Interpretasi Rules}

Setelah proses pembentukan rules a sosiasimenggunakan algoritma Predictive Apriori, rules yang dihasilkan akan di interpretasikan sesuai dengan kebutuhan dari permasalahan yaitu pemetaan profil mahasiswa berdasarkan masing-masing Prodi, sehingga kombinasi-kombinasi yang tidak sesuaikebutuhan akan dihilangkan dari rule set.

\section{Hasil dan Pembahasan}

Dari total rules yang telah dihasilkan oleh metode Predictive Apriori yang berjumlah 44456 rules, tidak semua dari rules tersebut yang akan digunakan untuk ditera pkan dan disampaikan kepada pengambil keputusan strategis atau dalam hal ini tim pemasaran danjuga nilaiakurasidari setiap rules-nya harus yang di atas 90\% (0.9). Proses interpretasi dari rules yang didapatkan harus disesuaikan dengan hasil yang diharapkan untuk digunakan selanjutnya. Total terdapat 85 rules yang disaring dari total rules yang dihasilkan oleh metode Predictive Apriori. Contoh sampel dari rules hasil penyaringan dapat dilihat pada Tabel 3 berikut ini.

Tabel 3. Hasil penyaringan rules.

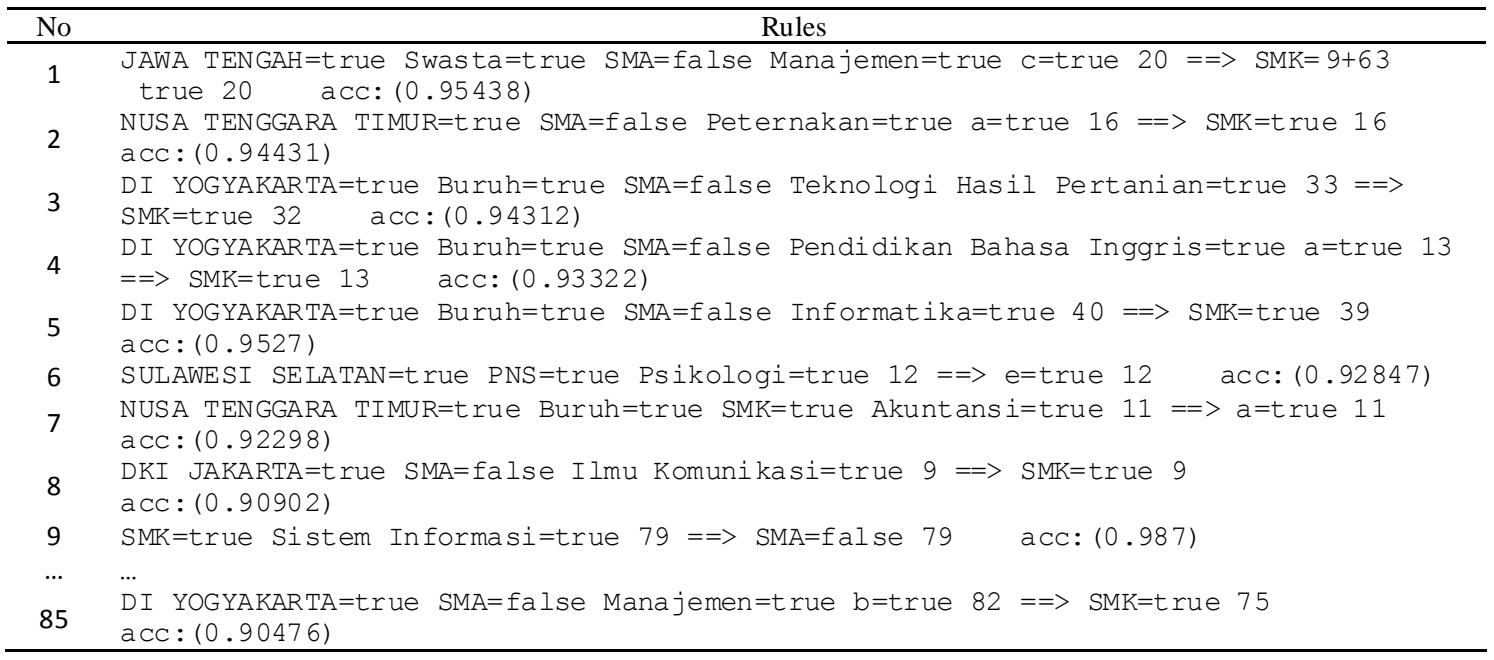

Dari Tabel 3 dapat dilihat hasil dari penyaringan rules-rules yang relevan dengan pemecahan masalah yang ada pada penelitian ini dengan mengambil rules-rules yang mengandung attribut Prodi dengan nilai a kurasi minimum 90\% (0.9). dari keseluruhan hasil peny aringan rules yang dilakukan, ternyata belum mewakili profiling untuk setiap Prodi yangada. berikut:

Contoh dari interpretasi rules yang dihasilkan dari metode Predictive Apriori adalah sebagai

Rule $1:$ Jawa Tengah $=$ true, Swasta $=$ true, $\mathrm{SMA}=$ false, Manajemen $=$ true, $\mathrm{c}=$ true, $\mathrm{SMK}=$ true.

Interpreta sinya adalah = Maha siswa yang memilih Prodi Manajemen Sebagian besar bera sal dari SMK di Jawa Tengah yang berasal dari keluarga berlatar belakang pekerjaan Swasta dan kategori penghasilan C" 
(di mana $\mathrm{C}$ merupakan kategori pendapatan yang ada di rentan 2.5 - 3 juta rupiah). Dari pengetahuan tersebut, langkah yang dapat dilakukan untuk meningkatkan efektivitas promosi perguruan tinggi adalah melakukan roadshow ke SMK yang berada di Jawa Tengah untuk memperkuat intake mahasiswa dari wilayah tersebut untuk Prodi Manajemen. Terkait dengan la tarbelakangekonomimahasiswa manajemen yang terpola bera da dikategori C, maka tidak perlu dilakukan diskon pendaftaran a tau beasiswa pendaftaran karena sudah dianggap mampu. Contoh lain dari interpretasi rule menjadi saran strategi promosi adalah rules 4: DI Yogyakarta $=$ true, Buruh $=$ true, Pendidikan Bahasa Inggris $=$ true, a $=$ true, $\mathrm{SMK}=$ true . Interpretasinya adalah = Mahasiswa Pendidikan Bahasa Inggris sebagian besar berasal dari Yogyakarta yang orang tuanya bekerja sebagaiburuh dan kategori pendapatan bera da pada kategoria (berada di range $0-1$ juta rupiah). Sehingga strategi marketing-nya untuk dapat memperkuat animo calon mahasiswa untuk Prodi tersebut adalah memberikan diskon atau promo tertentu pada saat roadshow di Yogyakarta dan di sekolah SMK untuk siswa -siswa sekolah yang bera sal dari keluarga yang a da di kategori ekonomi "a".

Hasil dari penelitian ini nantinya akan menjadi usulan dan pengetahuan yang dapat digunakan untuk teknis strategi pemasaran tergantung pada profil mahasiswa pada setiap Prodi untuk memperkuat promosi perguruan tinggi. Profil mahasiswa yang dimaksud adalah demografi mahasiswa seperti asal daerah a sal sekolah dan juga latar belakang ekonomi keluarga yang dilihat dari kategori pekerjaan orang tua dan kategoripendapatan orang tua.

\section{Kesimpulan}

Dari permasalahan yang dikemukakan sebelumnya bahwa pola dari profil mahasiswa dapat memudahkan dan mengoptimalkan kinerja dari tim marketing universitas dalam pemasaran dan promosi perguruan tinggi dapat diselesaikan menggunakan model association rule mining. Meskipun masih belum terpetakan secara adil untuk setiap Prodi dan sesuai yang diharapkan bahwa setiap Prodi akan memiliki profil yang khas dari sisi demografis maha siswanya, ka rena terdapat missing values sehingga data yang real tidak dapat digunakan dan persebaran mahasiswa setiap Prodi yang jumlahnya bisa jadi tidak merata sehingga frekuensi dari setiap itemset tidak dapat di ekstrak sepenuhnya. Hasil ini akan diharapkan dapat membantu dalam strategi promosi perguruan tinggi ke depannya.

Saran untuk kelanjutan dari penelitian ini ada lah dengan menggunakan jumlah attribute yang lebih banyak lagi dan mencoba model-modeldata mining gabungan untuk mengoptimalkan hasil seperti proses balancing data untuk masing-masing Prodi menggunakan Class Balancing Methods.

\section{Daftar Pustaka}

[1] Pddikti, "Grafik Jumlah Perguruan Tinggi," 2020. [Online]. Available: Https://Forlap.Ristekdikti.Go.Id/Perguruantinggi/Homegraphpt. [Acces sed: 10-Mar-2020].

[2] P. Kotler And K. L. Keller, Marketing Management, 15th Ed. Pearson Education Inc., 2016.

[3] V. Dhar, "Data Science And Prediction," Commun. Acm, Vol. 56, No. 12, Pp. 64-73, 2013, Doi: $10.1145 / 2500499$.

[4] J. Leek, “The Key Word In 'Data Science' Is Not Data, It Is Science,” 2012. [Online]. Available: Https://Simplystatistics.Org/2013/12/12/The-Key-Word-In-Data-Science-Is-Not-Data-It-IsScience/.

[5] I. H. Witten, E. Frank, And M. A. Hall, Data Mining: Practical Machine Learning Tools And Techniques, 3rd Ed. San Francisco, Ca, Usa: Morgan Kaufmann Publishers Inc., 2011.

[6] L. C. Yu, C. L. Chan, C. C. Lin, And I. C. Lin, "Mining Association Language Patterns Using A Distributional Semantic Model For Negative Life Event Classification," J. Biomed. Inform., Vol. 44, No. 4, Pp. 509-518,2011, Doi: 10.1016/J.Jbi.2011.01.006.

[7] S. Yakub, "Analisis Data Mining Untuk Strategi Promosi Produk Kosmetik Di Wardah Kosmetik Menggunakan Metode Apriori," Vol. 3, No. 1, Pp. 163-181,2020.

[8] U. Baetulloh, A. I. Gufroni, And R. -, "Penerapan Metode Association Rule Mining Pada Data Transaksi Penjualan Produk Kartu Perdana Kuota Internet Menggunakan Algoritma Apriori,” Simetris J. Tek. Mesin, Elektro Dan Ilmu Komput., Vol. 10, No. 1, Pp. 173-188, 2019, Doi: 10.24176/Simet.V10i1.2890.

[9] A. F. Afif, E. R. Swedia, And M. Cahyanti, "Implementasi Algoritma Association Rule Untuk Promosi Produk Berbasis Website Pada BengkelDelta Jaya Motor,” J. Ilm. Teknol. Dan Rekayasa, Vol. 24, No. 2, Pp. 152-160, 2019, Doi: 10.35760/Tr.2019.V24i2.2034.

[10] Y. Apridonal, "Penerapan Data Mining Menggunakan Metode Assiciation Rule Dengan Algoritma Apriori Untuk Analisa Pola Penjualan Barang,” Jurteksi, Vol. V, No. 2, Pp. 193-198, 2019.

[11] H. Kusumo, E. Sediyono, And M. Marwata, "Analisis Algoritma Apriori Untuk Mendukung Strategi Promosi Perguruan Tinggi," Walisongo J. Inf. Technol., Vol. 1, No. 1, P. 49, 2019, Doi: 
10.21580/Wjit.2019.1.1.4000.

[12] H. Maulidiya, A. Jananto, G. Special, I. A. Bawang, M. Seda p, And M. Asosiasi, “Asosiasi Data Mining Menggunakan Algoritma Apriori Dan Fp-Growth Sebagai Dasar Pertimbangan Penentuan Paket Sembako,"Pp. 978-979, 2020.

[13] R. J. A. Little And D. B. Rubin, Statistical Analysis With Missing Data. New York, Ny, Usa: John Wiley \&Amp; Sons, Inc., 1986.

[14] S. Zhang, "Nearest Neighbor Selection For Iteratively Knn Imputation,” J. Syst. Softw., Vol. 85, No. 11, Pp. 2541-2552, 2012, Doi: 10.1016/J.Jss.2012.05.073.

[15] T. Data Detective, "Preprocessing: Encode And Knn Impute All Categorical Features Fast," 2019.

[16] T. Scheffer, "Finding Association Rules That Trade Support Optima lly Aga inst Confidence," Intell. Data Anal., Vol. 9, No. 4, Pp. 381-395, 2005, Doi: 10.3233/Ida-2005-9405. 